\title{
A CONSTRUÇÃO DO PLANO NACIONAL DE EDUCAÇÃo E PROCESSO DELIBERATIVO EM PEQUENOS MUNICÍPIOS NO BRASIL ${ }^{1}$
}

\author{
Ronaldo Baltar (UEL) ${ }^{2}$ \\ Cláudia Siqueira Baltar (UEL) ${ }^{3}$
}

\section{RESUMO}

O objetivo desse estudo é analisar a aplicabilidade do conceito de deliberação ao conjunto de ações propostas pelo Plano Nacional de Educação (PNE) para pequenos municípios brasileiros (municípios com população inferior a 100 mil habitantes). A participação, a deliberação e o controle social foram eixos norteadores para elaboração do PNE e dos Plano Municipais de Educação subsequentes. Contudo, o processo consultivo e a forma estruturada para elaboração dos Planos Nacional e Municipais (PME) levantam aspectos importantes para se questionar a capacidade de formulação de um processo deliberativo. $\mathrm{O}$ estudo compara as diretrizes do PNE, as propostas dos PME e o limite imposto pela a realidade dos municípios, a partir do estudo de indicadores econômicos, educacionais e populacionais. O processo deliberativo não contemplou a realidade dos municípios, criando metas e estratégias que não são aplicáveis ou alcançáveis para a maioria dos pequenos municípios. Por outro lado, as proposições municipais não estão presentes na proposta nacional, traçada a partir de interesses corporativos e partidários.

Palavras-chave: Deliberação, Educação, Políticas Públicas.

\section{INTRODUÇÃO: DELIBERAÇÃO E PARTICIPAÇÃO}

A problematização do percurso entre a formulação do Plano Nacional de Educação (PNE), aprovado em 2014, e os Planos Municipais de Educação (PME), aprovados em 2015, requer um critério de avaliação, pois trata-se de buscar identificar a distância entre as metas e estratégias nacionais e as prioridades da realidade local, sobretudo no que se refere aos municípios com menos de 100 mil habitantes. Essa não é uma tarefa simples, não apenas pela complexidade das questões que envolvem a educação, mas também pela complexidade do processo de construção dos Planos Nacional, Estaduais e Municipais.

De modo geral, vamos tratar esse processo de construção do PNE como a tentativa de construção de um processo deliberativo. A definição e, consequentemente, a avaliação de um processo deliberativo tem sido objeto de profundo debate acadêmico nas últimas quatro décadas. A literatura sobre o tema é ampla, mas uma síntese desse debate por ser encontrada na discussão elaborada por Abelson et. Al. (Abelson et al., 2003). Os autores trabalham com

\footnotetext{
${ }^{1}$ Trabalho apresentado no XI Seminário de Pesquisa em Ciências Humanas (SEPECH); GT-6. Deliberação, Políticas Públicas e Formação de Educadores. Universidade Estadual de Londrina, 2016.

${ }^{2}$ baltar@uel.br

33cbaltar@uel.br
} 
enfoque na formulação de políticas para a área da saúde, mas o quadro conceitual e a proposta de avaliação são aplicáveis a outras áreas, no caso a educação.

A primeira constatação apresentada pelos autores é a conjugação de discursos entre acadêmicos e gestores sobre a importância da participação como ferramenta de política pública. Trata-se da efervescência de uma "agenda da participação pública". Os autores têm por referência países europeus, mas a reflexão se aplica ao Brasil, embora com algumas especificidades.

O debate sobre deliberação no Brasil tem uma literatura significativa. Mas, de modo geral, segue o que Abelson et al. (2003) denominam de "discussão normativa sobre deliberação", cujo foco está mais na confrontação de definições, do que em processos concretos de tomadas de decisão. Trabalhos como os de Faria (2000), Miguel (2001), Avritzer (2009) e Guariglia (2011) exemplificam essa tendência.

A discussão normativa sobre o conceito de "deliberação" em si é bastante extensa. A literatura brasileira reproduz um debate clássico, no qual há tantas definições quanto autores dispostos a enfrentar os problemas, como se pode observar na oposição de Cooke (2000) e Sanders (1997). Um dos pontos principais de discordância está no lugar da "representação" dentro do sistema deliberativo.

Ao lado desse debate normativo no Brasil, mais circunscrito aos meios acadêmicos, há um conjunto de trabalhos que aproxima "processos deliberativos" de "participação popular". Esses estudos ganham força com as abordagens sobre movimentos sociais dos anos 80 e 90. Sobretudo após 2003, observou-se a emergência de trabalhos que têm se concentrado na defesa de práticas participativas governamentais específicas, com um corte partidário delimitado. Um estudo de caso bem representativo dessa abordagem pode ser visto no estudo de Faria (2006) sobre o processo de Orçamento Participativo do Rio Grande do Sul, caso que se tornou modelo de referência para as análises sobre políticas participativas no país.

Essa abordagem difere dos estudos acadêmicos mais normativos por se concentrar em estudos mais descritivos sobre as formas definidas como participativas. Nesse tipo de abordagem o conceito de deliberação assume uma certa formulação teórica, que procura associar genericamente democracia com participação.

Abelson et. al. (2003) procuram mostrar que a convergência em torno da "agenda da participação", que ganhou corpo na virada do século XX para o século XI, surgiu de uma combinação de fatores. Desde o fortalecimento de concepções ideológicas, que procuravam ancorar o sentido de "legitimidade democrática" na participação popular, até concepções mais pragmáticas. Essas últimas, defendiam que a participação popular na gestão pública seria uma forma de "educação" dos cidadãos para a aceitação de limites à ação do Estado. Conhecedores dos dispêndios e custos das decisões estatais, esperavam os "pragmáticos" que a população aceitasse de forma mais "consciente" uma gestão pública mais "racional", isso é, como menos gastos públicos e menos controle sobre os negócios privados. Em ambos os casos, havia uma presunção de que a "participação popular" seria um substituto para o "capital social". Essa discussão tem como eixo o trabalho de referência de Pateman (1970).

No caso brasileiro, a ideia de participação teve um sentido diferente. Houve uma associação entre as ideias de deliberação e participação, colocando quase como ponto de oposição a ideia de democracia representativa. A democracia deliberativa, associada à 
democracia popular ou democracia participativa, dividia a ideia de ação política militante da tradicional visão de representação político-partidária. O estudo de Faria (2010) apresenta de forma bem sistematizada as divergências entre o que a autora definiu como "ativistas" e "deliberativos".

\section{A PARTiCiPAÇÃo NO PROCESSO DE CONSTRUÇÃo do PLANO NACIONAL DE EDUCAÇÃO}

O processo de participação é o cerne discursivo das propostas de construção dos Planos Nacionais, Estaduais e Municipais de Educação. Mas a realidade demonstra que são processos distantes de qualquer perspectiva de democracia deliberativa.

Os Planos Educacionais têm um forte discurso calcado em uma noção de "gestão democrática", que por sua vez está amparada na ideia de participação. Atingir as metas para a qualidade da educação é uma consequência da participação. A gestão democrática na educação seria o estabelecimento de formas institucionais de participação no planejamento, execução e monitoramento das ações educacionais em todos os âmbitos, da escola ao governo.

A literatura que aborda a elaboração dos Planos de Educação e os problemas de gestão participativa é tão extensa quanto os estudos sobre deliberação e participação. O trabalho de Souza (2013), faz uma das dificuldades de implementação do PNE 2001-2010. O autor também procura traçar uma avaliação preliminar do Plano 2014-2024. Em seu estudo, Souza (2013) faz um sistematizado balanço da literatura e mostra as diferentes interpretações sobre o processo de construção e os resultados do Plano Nacional de Educação.

Além das questões apontadas por Souza (2013), do ponto de vista dos pequenos municípios, a avaliação do processo de representação na Conferência Nacional de Educação - CONAE privilegiou determinados atores com atuação nacional, em detrimento da participação real de professores, pais e estudantes. A CONAE foi realizada em 2010, como etapa fundamental de construção do Plano Nacional de Educação, sob o ponto de vista de um processo de gestão democrática e participativa, e para alguns também deliberativa.

Fundamentalmente o processo de participação na CONAE, como de resto em todas as conferências temáticas promovidas pelo Governo Federal, obedeceu a sequência preparatória, com Conferências Municipais (Intermunicipais ou Regionais), Conferências Estaduais e, por fim, a Conferência Nacional. No caso da CONAE, a representação oriunda dos estados e municípios compôs os delegados eleitos. De acordo com os dados disponíveis sobre os delegados presentes à Conferência, todos os estados estiveram representados em quantidade proporcional ao tamanho populacional. Houve uma representação mínima que não criou disparidades muito exageradas entre estados mais e menos populosos. O peso dos delegados da Educação Básica foi expressivo, com mais da metade dos delegados, seguido da representação da Educação superior e Educação Profissional.

A representação por cidades, dentro dos Estados, também apresenta uma diversificação grande. De acordo com os dados da CONAE - 2010, haviam mais de 550 municípios representados. Pode-se ponderar que esse número representa aproximadamente $10 \%$ dos 5.557 municípios do país. Mas, levando-se em consideração a dificuldade logística de uma 
conferência com tantos delegados, além do fato de haver várias representações de Regionais de Ensino, pode-se considerar que a abrangência nacional esteve representada na CONAE.

\begin{tabular}{lll} 
UF & Delegados Natos & $\mathbf{\%}$ \\
\hline DF & 28 & $40,6 \%$ \\
SP & 8 & $11,6 \%$ \\
PE & 6 & $8,7 \%$ \\
PR & 6 & $8,7 \%$ \\
MG & 4 & $5,8 \%$ \\
GO & 3 & $4,3 \%$ \\
RS & 3 & $4,3 \%$ \\
RJ & 2 & $2,9 \%$ \\
MT & 2 & $2,9 \%$ \\
CE & 1 & $1,4 \%$ \\
TO & 1 & $1,4 \%$ \\
MA & 1 & $1,4 \%$ \\
BA & 1 & $1,4 \%$ \\
PA & 1 & $1,4 \%$ \\
AM & 1 & $1,4 \%$ \\
MS & 1 & $1,4 \%$ \\
\hline Total & & $\mathbf{1 0 0 , 0} \%$ \\
Geral & $\mathbf{6 9}$ & \\
\hline
\end{tabular}

Tabela 1 - Delegados Natos na Conferência Nacional de Educação por Estado, CONAE 2010

Fonte: tabulação própria a partir dos dados da CONAE 2010. Disponível em $<$ http://conae.mec.gov.br/index.php?option=com_content\&view=article\&id=67\&Itemid= 65 $>$ Acessado em 26/02/2016

Contudo, a condução dos temas e dos debates da Conferência se dá pelos delegados que representam categorias organizadas e as instâncias federais de gestão da educação. De acordo com a Tabela 1, pode-se observar que os delegados natos situados ou que atuam no Distrito Federal tem um peso grande na distribuição dos representantes. Esse grupo, efetivamente, representa os condutores do processo de "deliberativo" na Conferência, são os formuladores e detentores das informações técnicas, da agenda e da pauta de discussões. Também, nesse grupo encontra-se o principal papel de mediação e sistematização do conjunto de debates travados ao longo da Conferência.

Quando se observa a distribuição por categoria de representação, os membros do Poder Executivo Federal compõem 53\% dos delegados natos do Distrito Federal, de acordo com os dados da CONAE - 2010. Em todas as demais delegações estaduais esse número é mais equilibrado, sem um peso tão grande de delegados representantes do poder executivo, seja federal, estadual ou municipal. 


\begin{tabular}{lll} 
Representação & Núm. de delegados & $\mathbf{\%}$ \\
\hline EXECUTIVO & 17 & $24,6 \%$ \\
FED. & 17 & $18,8 \%$ \\
SINDICAL & & \\
TRAB. & 13 & $11,6 \%$ \\
DIRIGENTES & & \\
UNIV. & 8 & $8,7 \%$ \\
EXECUTIVO & & $5,8 \%$ \\
EST. & 6 & $5,8 \%$ \\
MOV. SOCIAL & 4 & $5,8 \%$ \\
MOV. & & $5,8 \%$ \\
ESTUDANTIL & 4 & $4,3 \%$ \\
SINDICAL EMP. & 4 & $2,9 \%$ \\
LEGISLTATIVO & 4 & \\
ACADEMIA & 3 & $2,9 \%$ \\
MOV. DE PAIS & 2 & \\
EXECUTIVO & & $2,9 \%$ \\
MUNIC. & 2 & $\mathbf{1 0 0 , 0} \%$ \\
MOV. & 2 & $\mathbf{6} \%$ \\
EDUCAÇÃO & 2 & \\
Total Geral & $\mathbf{6 9}$ & \\
\hline
\end{tabular}

Tabela 2 - Delegados Natos por Categoria de Representação, CONAE - 2010

Nota: Classificação feita pelo autor, com base na representação descrita no documento fonte: Representantes do Poder Executivo Federal; Movimento Sindical de Trabalhadores; Dirigentes de Universidades; Poder Executivo Estadual; Movimento Social; Movimento Estudantil; Representante Sindical Patronal; Representantes do Legislativo (Câmara e Senado); Acadêmicos; Movimentos de pais; Representantes do Poder Executivo Municipal; Representantes de Movimentos em prol da Educação.

Fonte: tabulação própria a partir dos dados da CONAE 2010. Disponível em $<$ http://conae.mec.gov.br/index.php?option $=$ com $\_$content\&view $=$article\&id=67\&Itemid $=65$ $>$ Acessado em 26/02/2016

A Tabela 2 mostra distribuição de delegados natos por categoria de representação. Há um peso grande de delgados do Poder Executivo Federal, ligados ao Ministério da Educação e suas diversas Secretarias. Em seguida, estão os representantes sindicais de trabalhadores. Esse conjunto de 69 pessoas, embora bem menor em número do que os 2.000 delegados eleitos nos Estados, possuíam o informações e capacidade de pautar a agenda da Conferência. Em torno da composição de interesses desses atores gravitavam os demais delegados. Subjacente aos debates, estavam interesses partidários, que articulavam a disputa de posição dentro da CONAE.

Esse processo, certamente participativo, mas não deliberativo, transformou a Conferência em uma batalha por território semântico, tendo como eixo articulador a proposição inicial do MEC e de entidades parceiras. A disputa era por posicionamento de palavras e frases. Mais representavam o enfrentamento de posicionamentos ideológicos, do 
que a representação de problemas efetivos, sobretudo no que se refere à realidade dos municípios menores.

No próprio documento base, preparatório para a CONAE, bem como no Plano Nacional da Educação, aprovado em 2015, o termo participação é utilizado frequentemente, como sinônimo de gestão democrática. O termo deliberação aparece poucas vezes no documento, sempre como sinônimo de decisão, por oposição ao entendimento de "posicionamento consultivo".

De fato, há uma relação entre gestão democrática e resultados acadêmicos. Trabalhos como o de Vidal e Vieira (2011) apresentam uma discussão detalhada como se relacionam as ações administrativas, as práticas pedagógicas e os impactos sobre o IDEB. A participação é fundamental para o processo democrático, mas não é condição suficiente. A deliberação, como processo de construção comum de entendimento sobre a natureza dos problemas a serem enfrentados e as possíveis alternativas de ação, é imprescindível. $\mathrm{O}$ processo de construção do PNE demonstra os limites estratégicos da política nacional participativa, por ignorar a necessidade de construção de processo deliberativos de base.

\section{CONSIDERAÇÕES FINAIS: OS LIMITES DA DELIBERAÇÃO SEM INFORMAÇÃO}

As questões levantadas pelos municípios não estão presentes, ou se apresentam de maneira tênue, nos debates da CONAE. Por reflexo, o PNE trata da visão nacional dos gestores federais, especialistas e representantes sindical. Os problemas reais e as diferentes situações vividas pelos municípios não estão representada no Plano Nacional. Os Planos Estaduais e Municipais, construídos em 2015 sob o mesmo princípio do PNE, apenas reproduzem em grande parte o que já havia sido acordado no PNE. A exceção de outras batalhas semânticas, que mobilizou outros atores políticos não envolvidos na discussão da CONAE, os Planos Municipais seguem, como por imposição, as linhas gerais traçadas pelas Metas e Estratégias do PNE. O tempo para o debate e a construção das ações próprias foi diminuto. Para cumprir a Lei, os municípios recorreram ao suporte lhes esteve disponível e entregaram seus documentos, como promessas de cumprimento de metas para os próximos 10 anos.

Para traçar as linhas que formam a perspectiva dos Planos decenais de Educação, há dois pontos de fuga: elevar o IDEB e consolidar a gestão democrática como política de estado.

O IDEB é um indicador bastante discutido, conforme demonstram, entre outros estudos, os trabalhos de Soares e Xavier (2013) e Mesquita (2012). Tem uma composição ideológica. Mais do que uma correlação estatística, procura exprimir em números uma política governamental.

Tomando o IDEB como eixo, uma das premissas do Plano Municipal de Educação é a possiblidade de monitoramento a partir de indicadores quantitativos. A disponibilidade de dados educacionais produzidas e disponibilizadas pelo Instituto Anísio Teixeira (INEPMEC) despertou o interesse entre pesquisadores de várias áreas. Há uma vasta literatura discutindo diferentes formas de correlação entre os indicadores e variáveis socioeconômicas, como se pode constatar em trabalhos recente como de Schneider (2013), 
Júnior, Faria; Lima, (2012), e Alves e Soares (2013). Mas poucos se debruçam a sobre a forma como as informações devem ser tratadas para sustentar um processo deliberativo.

$\mathrm{O}$ uso dos indicadores educacionais em si, como fonte de formulação de políticas, tem sido um tema debate apurado entre especialista na área. Veja-se, por exemplo as considerações levantadas por (Bottani, 1998), em artigo publicado em 1998, que aborda a importância e os limites do uso de dados educacionais disseminados pela Organização de Cooperação e de Desenvolvimento Econômico. Discussão que a OCDE trouxe recentemente ao centro do debate com a publicação do seu relatório de 2013, discutindo como avaliar os benefícios da educação no processo de desenvolvimento social, comparando-se indicadores de escolaridade com longevidade, por exemplo (OCDE, 2013).

A distância entre o documento da CONAE, o PNE e a realidade municipal não depreende apenas da avaliação do conteúdo dos documentos. A falta de um processo deliberativo implicou na desarticulação dentre as ações no plano federal, estadual de municipal.

Uma política estratégica decenal para a educação não pode ignorar que há fatores estruturais que criram disparidades regionais e locais (Breen; Jonsson, 2005). No caso brasileiro, a questão estrutural é identificável, ao se observar a relação entre o IDEB (anos finais e anos iniciais) e a proporção de crianças pobres por municípios no Brasil, no caso, tomando-se como referência apenas aqueles com menos de 100 mil habitantes.

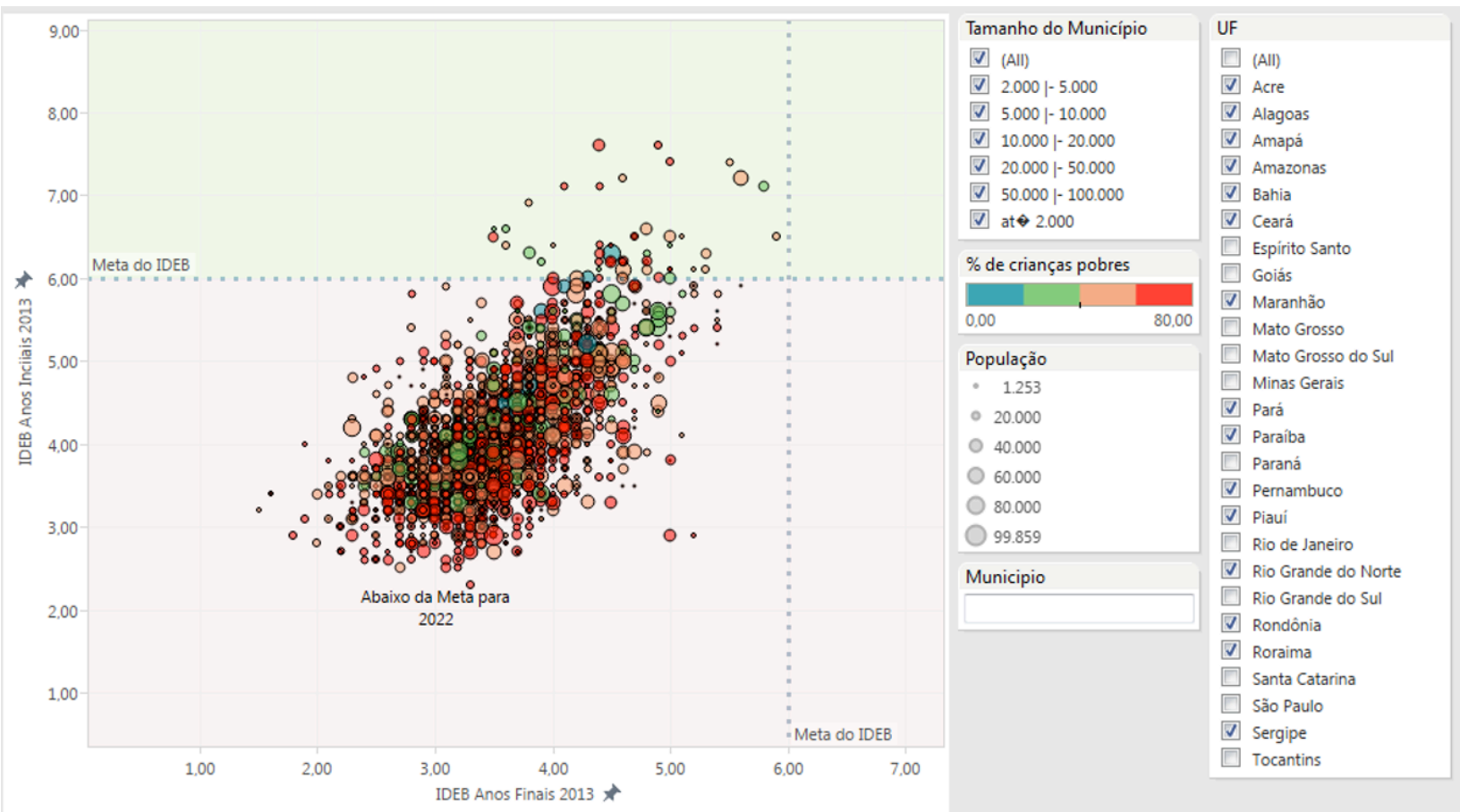

Gráfico 1 - IDEB anos iniciais e fiais por \% de crianças pobres. Região Norte e Nordeste, Municípios até 100 mil hab.

Fonte: tabulação própria a partir dos dados do INEP - Censo Educacional, 2013 e IBGE Censo Populacional, 2010. 
O Gráfico 1 mostra a distribuição de municípios com menos de 100 mil habitantes das Regiões Norte e Nordeste em relação à meta estipulada para o IDEB, que aparece no quadro superior direito. Observa-se que a grande maioria dos municípios se encontram no quadro inferior esquerdo, longe da meta para os anos iniciais e finais. É predominante nos municípios a existência de uma taxa de crianças pobres acima de $50 \%$.

O Gráfico 2 demonstra a mesma informação para os municípios das Regiões Sul e Sudeste. Observa-se que já existe um pequeno número de municípios dentro da meta. Um grande número acima da meta para os anos iniciais, mas muitos ainda abaixo da meta par os anos finais. A expressiva maioria dos municípios tem uma porcentagem de crianças pobres abaixo de $50 \%$

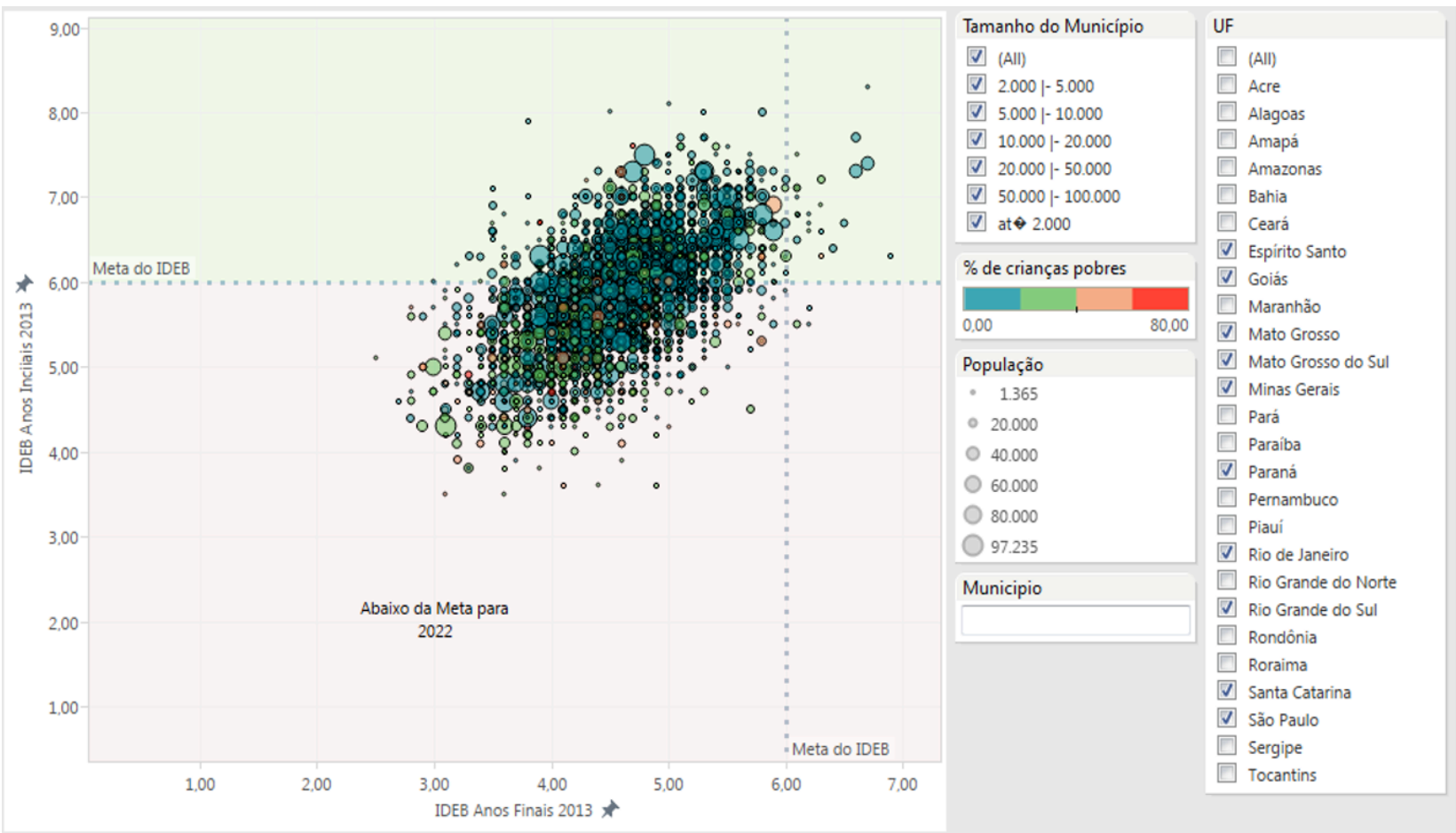

Gráfico 2 - IDEB anos iniciais e fiais por \% de crianças pobres. Região Sul e Sudeste, Municípios até 100 mil hab.

Fonte: tabulação própria a partir dos dados do INEP - Censo Educacional, 2013 e IBGE Censo Populacional, 2010.

O Gráfico 3 mostra a mesa situação para o Estado do Paraná, que apresenta uma situação de distribuição da pobreza próxima a média das Regiões Sul (da qual faz parte) e Sudeste, ao mesmo tempo que que possui uma situação em relação ao IDEB mais distante da meta do que a média dessas regiões.

As três situações demonstradas nos Gráficos apontam para a existência de problemas estruturais, relacionados à pobreza, distribuição de renda e outros fatores, que afetam a educação. As resoluções desses fatores dependem de ações federais e estaduais. Pouco espaço cabe aos municípios, sobretudo em se tratando daqueles com população abaixo de 
100 mil habitantes, em termos de possibilidade de formulação de políticas de alcance macroestrutural.

Do mesmo modo, quando se toma o quadro do Estado do Paraná, a título de ilustração, observa-se que municípios com tamanho populacional e situação de pobreza similares possuem desempenho diferente em relação ao IDEB. Nesse caso, os fatores locais possivelmente estarão no âmbito da formulação de políticas e ações locais (ou intermunicipais).

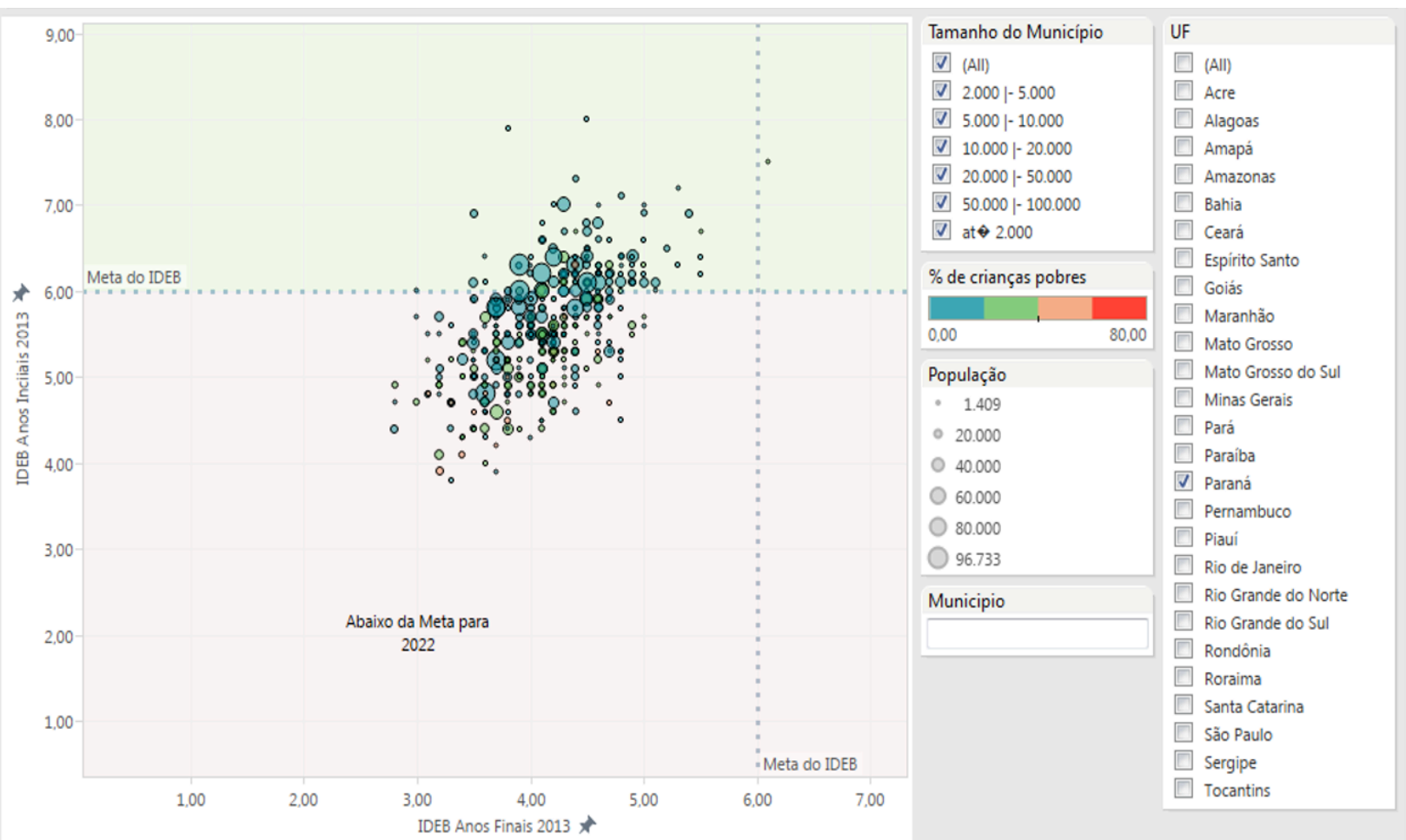

Gráfico 3 - - IDEB anos iniciais e fiais por \% de crianças pobres. Estado do Paraná, Municípios até 100 mil hab

Fonte: tabulação própria a partir dos dados do INEP - Censo Educacional, 2013 e IBGE Censo Populacional, 2010.

Mobilização e participação não são suficientes para garantir a gestão democrática. A construção de um processo deliberativo efetivo, com capacidade de identificação local de problemas e formulação de ações que estejam articuladas nas esferas federal, estadual e municipal é o requisito básico. Para tanto, faz-se necessária uma simetria de informações entre todos os atores e entes envolvidos no projeto. Desse modo, pode-se identificar a parcela de ações estruturais, a cargo do Plano Nacional e Estadual, e o conjunto de ações específicas que dizem respeito ao enquadramento de problemas locais. Os Planos Municipais de Educação e os Planos Estaduais, elaborados e aprovados em 2015, reproduzem a batalha semântica dos atores federais da CONAE 2010, acrescidos de uma lista pontual de aspirações locais. Falta a articulação, que se espera, venha a ser construída nas etapas de monitoramento previstas para os próximos anos. 


\section{BIBLIOGRAFIA}

ABELSON, J.; FOREST, P. G.; EYLES, J.; SMITH, P.; MARTIN, E.; GAUVIN, F. P. Deliberations about deliberative methods: issues in the design and evaluation of public participation processes. Social Science Medicine, v. 57, n. 2, p. 239-251, 2003.

ALVES, M. T. G.; SOARES, J. F. Contexto escolar e indicadores educacionais: condições desiguais para a efetivação de uma política de avaliação educacional. Educ. Pesqui., v. 39, n. 1, p.177-194, mar. 2013.

AVRITZER, Leonardo. Democracy and the public space in Latin America. Princeton: Princeton University Press, 2009.

BOTTANI, N. Ilusão ou ingenuidade?: Indicadores de ensino e políticas educacionais. Educ. Soc., v. 19, n. 65, dez. 1998.

BREEN, R.; JONSSON, J. O. Inequality of Opportunity in Comparative Perspective: Recent Research on Educational Attainment and Social Mobility. Annu. Rev. Sociol., v. 31. n. 1, p. 223-243, ago. 2005.

COOKE, M. Five arguments for deliberative democracy. Political Studies, v. 48. n.5, p. 947-969, 2000.

DOURADO, Luiz Fernandes. A Conferência Nacional de Educação, o Plano Nacional e a construção do Sistema Nacional de Educação. Revista Brasileira de Política e Administração da Educação, v. 25, n. 2, 2011. Disponível em http://seer.ufrgs.br/index.php/rbpae/article/view/19502/11326 Acessado em 26/02/2016.

FARIA, Cláudia Feres. Democracia deliberativa: Habermas, Cohen e Bohman. Lua Nova, n. 50, p. 47-68, 2000.

FARIA, Cláudia Feres. Fóruns Participativos, Controle Democrático e a Qualidade da Democracia no Rio Grande do Sul: a Experiência do Governo Olívio Dutra (1999-2002). Opinião Pública, v. 12, n. 2, 2006.

FARIA, Cláudia Feres. O Que Há de Radical na Teoria Democrática Contemporânea: Análise do Debate entre Ativistas e Deliberativos. Revista Brasileira de Ciências Sociais, v. 25, n. $73,2010$.

FARIA, Claudia Feres; SILVA, Viviane Petinelli; LINS, Isabella Lourenço. Conferências de Políticas Públicas: Um Sistema Integrado de Participação e Deliberação? Rev. Bras. Ciênc. Polít. n. 7, p. 249-284, 2012. 
GUARIGLIA, O. La Democracia en América Latina: la alternativa entre populismo y democracia deliberativa. Isegoría, v. 0, n. 44, p. 57-72, jun. 2011.

GUTMANN, Amy; THOMPSON, Dennis. O que significa democracia deliberativa. Revista brasileira de Estudos Constitucionais, v. 1, 2007.

JÚNIOR, F. T., FARIA, V. B.; LIMA, M. A. de. Indicadores de fluxo escolar e políticas educacionais: avaliação das últimas décadas. Est. Aval. Educ., v. 23, n. 52, ago. 2012.

MESQUITA, S. Os resultados do Ideb no cotidiano escolar. Ensaio: Avaliação e Políticas Públicas em Educação, v. 20, n. 76, p. 587-606, set. 2012.

MIGUEL, L. F. Promessas e limites da democracia deliberativa. Revista Brasileira de Ciências Sociais, v. 16, n. 46, p. 175-177, jun. 2001.

PATEMAN, C. Participation and Democratic Theory. Cambridge, Cambridge University Press, 1970.

PERES, A. J. d. S., RODRIGUES, E. G., SILVA, M. L. F., SANTOS, P. P.; SANTOS, R. D. PNE em Movimento Construindo Indicadores Educacionais nos municípios. Ministério da Educação, 2016.

SANDERS, L. M. Against deliberation. Political Theory, v. 25, n. 3, p. 347-376, 1997.

SCHNEIDER, G. Indicadores educacionais: uma análise frente à realidade paranaense. Jornal de Políticas Educacionais, v.6, n. 11, mar. 2013.

SOARES, J. F.; XAVIER, F. P. Pressupostos educacionais e estatísticos do Ideb. Educ. Soc., v. 34, n. 124, p. 903-923, 2013.

SOUZA, D. B. de. Avaliações finais sobre o PNE 2001-2010 e preliminares do PNE 20142024. Est. Aval. Educ., v. 25, n. 59, dec. 2013.

VIDAL, E. M.; VIEIRA, S. L. Gestão educacional e resultados no IDEB: um estudo de caso em dez municípios cearenses. Est. Aval. Educ., v. 22, n. 50, dez. 2011.

OCDE. What Are the Social Benefits of Education? Organisation for Economic CoOperation and Development, 2013. 